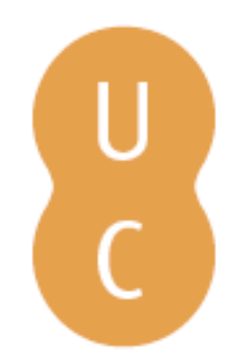

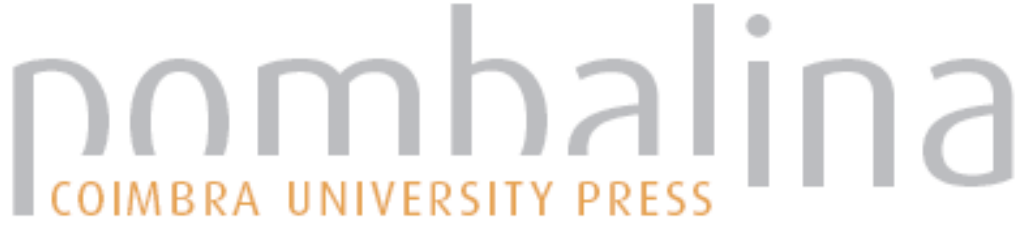

\section{A morte do casamento: mito ou realidade?}

\author{
Autor(es): $\quad$ Martins, Rosa Cândido
}

Publicado por: Imprensa da Universidade de Coimbra

URL

persistente: URI:http://hdl.handle.net/10316.2/38885

DOI: $\quad$ DOI:http://dx.doi.org/10.14195/978-989-26-1113-6_7

Accessed : $\quad$ 26-Apr-2023 12:43:47

A navegação consulta e descarregamento dos títulos inseridos nas Bibliotecas Digitais UC Digitalis, UC Pombalina e UC Impactum, pressupõem a aceitação plena e sem reservas dos Termos e Condições de Uso destas Bibliotecas Digitais, disponíveis em https://digitalis.uc.pt/pt-pt/termos.

Conforme exposto nos referidos Termos e Condições de Uso, o descarregamento de títulos de acesso restrito requer uma licença válida de autorização devendo o utilizador aceder ao(s) documento(s) a partir de um endereço de IP da instituição detentora da supramencionada licença.

Ao utilizador é apenas permitido o descarregamento para uso pessoal, pelo que o emprego do(s) título(s) descarregado(s) para outro fim, designadamente comercial, carece de autorização do respetivo autor ou editor da obra.

Na medida em que todas as obras da UC Digitalis se encontram protegidas pelo Código do Direito de Autor e Direitos Conexos e demais legislação aplicável, toda a cópia, parcial ou total, deste documento, nos casos em que é legalmente admitida, deverá conter ou fazer-se acompanhar por este aviso.

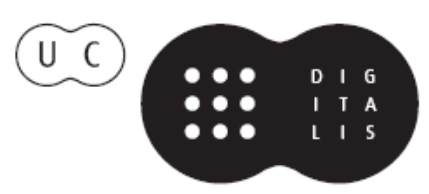




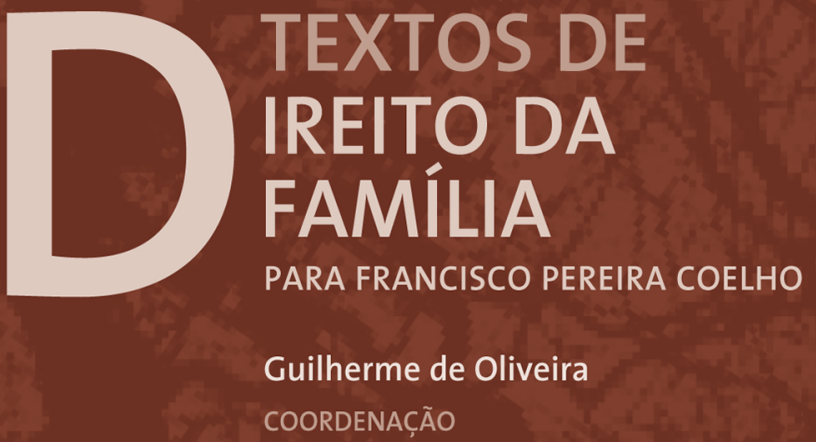




\section{A MORTE DO CASAMENTO: MITOOU REALIDADE? 1}

Rosa Cândido Martins

Assistente Convidada da Faculdade de Direito de Coimbra

Investigadora do Centro de Direito da Família

\section{Introdução}

A família tem sofrido ao longo das últimas quatro décadas transformações profundas não só quanto à sua estrutura mas também quanto às funções que desempenha. Na verdade, a família sofreu um complexo processo de mudança devido à influência de tendências demográficas, científicas, económicas, históricas e ideológicas² ${ }^{2}$ Neste processo a família foi perdendo muitas das suas funções tradicionais,

${ }^{1}$ É com enorme gosto que me associo a esta devida e justa homenagem ao Senhor Prof. Doutor Francisco Manuel Pereira Coelho. Embora nunca tenha sido sua aluna nem sua assistente, a vida e a obra do Senhor Prof. Doutor Pereira Coelho sempre me chegaram e influenciaram profundamente. Não podia, assim, deixar de participar nesta empresa ainda de um modo muito modesto com um texto já publicado (Martins, Rosa Cândido, La muerte del matrimónio: ¿mito o realidade en el Derecho Portugués, Anuario de la Faculdade de Dereito da Universidade da Coruña, n. ${ }^{\circ}$ 16, 2012, ISSN: 1138-039X, pp. 325334).

${ }^{2}$ Cf. M. A. Glendon, "Introduction: Family law in times of turbulence" in: VV. AA., M. A. Glendon, (ed.), International Encyclopaedia of Comparative Law: Persons and Family, Vol. IV, Tübingen - Dordrecht - Boston - Lancaster, Mohr Siebeck - Martinus Nijhoff Publishers, 2006, p. 3, F. Swennen, "O tempora, o mores! The evolving marriage concept and the impediments to marriage" in: VV. AA, M. ANTOKOLSKAIA, (ed.), Convergence and divergence of family law in Europe, Antwerpen - Oxford, Intersentia, 2007, p. 123. 
designadamente a função de prover à segurança e ao cuidado dos seus membros, a função de prover à sua subsistência e a função de transmitir o património de geração em geração ${ }^{3}$.

A maior parte destas funções foram total ou parcialmente assumidas pelo Estado e por outras instituições privadas ${ }^{4}$. O Estado passou a fornecer toda uma série de mecanismos de protecção social, como por exemplo benefícios da segurança social, subsídio de desemprego, de doença e de acidente, pensões de reforma, etc., que passaram a garantir aos indivíduos um "mínimo de existência". E, assim, os membros da família ficaram cada vez menos dependentes uns dos outros. A família deixou de ser uma "comunidade de necessidade", cujos membros estavam vinculados por uma "obrigação de solidariedade".

A perda ou pelo menos a partilha de algumas das funções tradicionais provocou várias mudanças na família. No que respeita ao aspecto estrutural, a família não é já vista como a "grande família" do passado mas sim como "família nuclear" composta por pai e mãe e seus filhos ${ }^{6}$. A família não apresenta mais uma estrutura hierárquica e autoritária baseada na diferenciação da capacidade civil e política dos cônjuges. Hoje, por imposição constitucional, marido e mulher têm iguais direitos e deveres quanto à capacidade civil e política e à manutenção e educação dos filhos; possuem iguais direitos e deveres conjugais e detêm os mesmos direitos quanto à administração e disposição do seu património7.

3 Cf. F. Pereira Coelho, G. Oliveira, Curso de Direito da Família, Vol. I, Coimbra, Coimbra Editora, 2008, pp. 100-101.

${ }^{4} \mathrm{Cf}$. M. A. Glendon, The new family and the new property, Toronto, Butterworths, 1981 , p. 1-2, E Beckgernsheim, "On the Way to a Post-Familial Family: From a Community of Need to Elective Affinities" in: VV. AA., A. DIDUCK (ed.), Marriage and Cohabitation. Regulating Intimacy, Affection and Care, Aldershot, Ashgate, 2008, p. 57.

5 Cf. E. BeCK-GERnSHeIM, "On the way..." cit., p. 57.

${ }^{6}$ Cf. F. Pereira Coelho, G. Oliveira, Curso... cit., p. 99.

7 Sobre o princípio constitucional da igualdade dos cônjuges, vide F. PEREIRA Coelho, G. Oliveira, Curso... cit., pp. 126-127, J. J. Gomes CANotilho, Vital 
Também o comportamento familiar não permaneceu intocado. Os costumes mudaram. As taxas de casamentos e de nascimentos começaram a diminuir enquanto que o número de divórcios, de uniões de facto e de nascimentos fora do casamento começaram a aumentar.

Todas estas transformações têm sido frequentemente interpretadas como o fim da família. Todavia esta profecia falhou ${ }^{8}$. A família continua a existir... mas em processo de transformação. A família está a adquirir uma "nova forma histórica". Está a nascer a "nova família"10.

Embora o novo conceito de família não seja unívoco pois co-existem vários tipos de família ${ }^{11}$ ao mesmo tempo num mesmo espaço, é possível encontrar um padrão comum entre estas várias famílias. A "nova família" é a família que descobriu os valores da intimidade e da afectividade; é a família que visa a educação e manutenção dos filhos e o apoio emocional e o desenvolvimento pessoal de todos os membros da família.

\section{A privatização do casal}

O aparecimento da "nova família" motivou a necessidade de um novo Direito da Família que pudesse acompanhar as suas mudanças. Assim, desde a década de 60 o Direito da Família nos países ocidentais tem sofrido igualmente um processo de transformação. Podem

\footnotetext{
MOREIRA, Constituição da República Portuguesa Anotada, Vol. I, Coimbra, Coimbra Editora, 2007, pp. 564-565, J. MIRANDA, R. MEdeIROS, Constituição Portuguesa Anotada, T. 1, Coimbra, Coimbra Editora, 2005, pp. 410-411.

8 Cf. G. THERBORn, Between sex and power. Family in the world, 1900-2000, London; New York, Routledge, 2006, 313.

9 Cf. E. BeCK-Gernsheim, "On the way..." cit., p. 57.

10 Cf. M. A. Glendon, The new family ... cit., p. 3.

11 Cf. M. A. Glendon, The new family ... cit., p. 4.
} 
apontar-se como valores que têm norteado as sucessivas adaptações à realidade da nova família a ideia de liberdade individual, a ideia de igualdade, os direitos das mulheres e os direitos humanos ${ }^{12}$. No entanto, o processo ainda não terminou.

O declínio da posição preponderante do casamento como principal fonte das relações familiares teve como reflexo um Direito da Família não centrado no casamento. A realidade mostra que há mais família para além da família conjugal ${ }^{13}$ : as relações de intimidade e de afectividade bem como a geração e a educação dos filhos podem hoje ter lugar fora da instituição do casamento sem a consequência da discriminação dos filhos nascidos fora do casamento ${ }^{14}$. Deste modo, o casamento e filiação deixaram de estar necessariamente ligados. Mais também já não se verifica a necessária identidade entre relação de afectividade e casamento. $\mathrm{Na}$ verdade, o reconhecimento legal da união de facto através da atribuição de efeitos semelhantes aos do casamento, a decrescente diminuição da desaprovação social e quase inexistência de sanções sociais e legais relativamente às relações sexuais fora do casamento contribuíram para a dissociação destes dois conceitos ${ }^{15}$.

A Sociologia tem sugerido o movimento no sentido de uma "privatização do casal"16. De acordo com esta tendência o casamento, baseado no amor e na realização pessoal de ambos os cônjuges, é

12 Cf. M. A. Glendon, "Introduction..." cit., p. 3.

13 Cf. J. D. PINHeIRo, O Direito da Família contemporâneo, Lisboa, AAFDL, 2008, p. 34 .

14 Cf. F. Pereira Coelho, G. Oliveira, Curso... cit., pp.103-104, G. Oliveira, "Transformações do Direito da Família" in: VV. AA., Comemorações dos 35 anos do Código Civil e dos 25 anos da Reforma de 1977, Vol. I, Coimbra, Coimbra Editora, 2004, p. 766.

15 Cf. M. GARRISON, "The Decline of Formal Marriage: Inevitable or Reversible?", Family Law Quarterly, Vol. 41, No. 3, 2007, p. 506.

16 Cf. S. ABOIM, "A formação do casal: formas de entrada e percursos conjugais", in: K. WALl (org.), Famílias em Portugal, Lisboa, ICS, 2005, p. 86. 
tido como um "assunto privado", uma relação íntima que apenas diz respeito a quem nela está envolvido.

A intervenção do Estado, através do estabelecimento de regras vinculativas quanto à constituição ${ }^{17}$ da relação matrimonial, definição dos seus efeitos a nível das pessoas dos cônjuges e do seu património e dos termos da sua dissolução tem-se tornado, neste contexto, cada vez menos justificada e aceite. Desta falta de justificação e aceitação resultou um declínio do poder regulativo do Estado no que respeita à constituição do casamento e à sua dissolução ${ }^{18}$.

Cada vez mais os casais parecem mostrar uma atitude de indiferença em relação a qualquer espécie de aprovação externa da sua relação. Assim, parecem recusar submeter-se aos valores pré-determinados estabelecidos pela Igreja e pelo Estado, deixando de aderir à "instituição do casamento"19.

As estatísticas mais recentes confirmam esta tendência demonstrando a diminuição da percentagem dos casais que escolhem o casamento e a percentagem crescente daqueles que escolhem a união de facto 20 .

\section{A morte do casamento?}

Quer isto significar a morte do casamento? Ou a sua desnecessidade como instituição jurídica e social?

17 Cf. D. COESTER-WALTJEn, M. COESTER, "Formation of marriage" (Chapter 3) in: M. A. GLENDON (ed.), International Encyclopaedia of Comparative Law: Persons and Family, Vol. IV, Tübingen; Dordrecht; Boston; Lancaster, Mohr Siebeck - Martinus Nijhoff Publishers, 1997, p. 160, SWEnNEN, F., "O tempora, o mores..." cit., pp. 123-124.

18 Cf. M. A., GLENDON, "Introduction..." cit., p. 7.

19 Cf. I. THÉRY, Couple, Filiation et parenté ajourd'bui. Le droit face aux mutations de la famille et de la vie priveé, Paris, Odile Jacob, 1998, p. 32.

20 Cf. S. LEITE, “A união de facto em Portugal”, Revista de Estudos Demográficos, n. ${ }^{\circ} 33,2003$, pp. 99100. 
O casamento não está morto nem está a morrer... está a transformar-se.

As duas razões principais que suportam a tese de que o casamento está longe de estar morto coincidem com duas tendências do Direito da Família: a "desregulação” do casamento, por um lado, e a "regulação" da união de facto, por outro lado.

\section{III.1. A "desregulação" do casamento}

Apesar do declínio do casamento, o Estado não o retira completamente da esfera pública remetendo apenas para a esfera privada das partes.

O Estado insiste em regular certos aspectos da relação matrimonial. Tendo em consideração a ideia de que o casamento oferece a estabilidade necessária para a educação dos filhos e reconhecendo que o casamento é um "importante símbolo" nas nossas sociedades, o Estado não tem a intenção de abolir o casamento como instituição legal e deixá-lo simplesmente à negociação privada dos cônjuges na determinação dos direitos e deveres conjugais; o Estado tenta tornar o casamento mais atractivo promovendo um regime legal "light".

Partindo do princípio de o casamento tradicional tem um regime legal "pesado"21 que apresenta níveis elevados de regulação da relação íntima dos cônjuges, o caminho a seguir parece ser o da "desregulação" do casamento. Esta tarefa, porém, pode assumir diversas formas. Na verdade, existem três modos de desenvolver um regime "light" para o casamento: primeiro, através da abolição de maior parte dos impedimentos legais do casamento; segundo, através da recusa ou mesmo da abstenção quanto à determinação

21 Cf. M. A, GLENDON, The transformation of family law. State, law, and the family in the United States and Western Europe, Chicago; London, The University of Chicago Press, 1989, pp. 32-33. 
e regulação dos efeitos da relação matrimonial; finalmente, através de uma espécie de facilitação da extinção do casamento.

Embora estes três modos de "desregulação" do casamento possam ter lugar em momentos diferentes, eles interagem necessariamente uns com os outros no mesmo processo de transformação do casamento. Com efeito, o facilitar a extinção da relação matrimonial tende a afectar a importância social e legal dos impedimentos matrimoniais ${ }^{22}$, bem como o significado dos direitos e deveres dos cônjuges. E do mesmo modo, as mudanças nas regras de constituição do casamento no sentido de permitir um mais amplo acesso à relação matrimonial implicam a necessidade de uma maior liberdade quanto à extinção da relação.

\section{III.1.1. A Reforma do Divórcio de 2008 em Portugal}

Um exemplo da tendência atrás referida da "desregulação" do casamento é a recente Reforma do Divórcio em Portugal. Tal reforma teve por objectivo revogar o regime tradicional do divórcio litigioso baseado na culpa de um dos cônjuges e assim introduzir o regime do divórcio sem culpa ${ }^{23}$.

O sistema de divórcio português foi e ainda é um sistema "pluralista" ${ }^{24}$, no sentido de que reconhece várias formas de divórcio. A lei anterior reconhecia apenas dois tipos de divórcio: o divórcio por mútuo consentimento e o divórcio litigioso.

22 Cf. D. Coester-Waltjen, M. Coester, "Formation of marriage..." cit., p. 4.

23 Veja-se o Preâmbulo do Projecto-lei n. ${ }^{\circ}$ 509/X. Sobre regime jurídico do divórcio, vide $\mathrm{R}$. LOBO XAVIER, Recentes alterações ao regime jurídico do divórcio e das responsabilidades parentais, Coimbra, Almedina, 2009, G. OLIVEIRA, "A nova lei do divórcio", Lex Familiae - Revista Portuguesa de Direito da Família, Ano 7, n. ${ }^{\circ} 13,2010$.

${ }^{24}$ Cf. K. BOele-WOelKi, F. FÉRrand, C. GONZÁleZ-Beilffuss, M. JÄNTERÄJAREnborg, N. Lowe, D. Martiny, W. PINTENS, Principles of European Family Law regarding divorce and maintenance between former spouses, Antwerp; Oxford, Intersentia, 2004, p. 13. 
O divórcio por mútuo consentimento consubstanciava-se num processo meramente administrativo que tinha início com a entrega de um requerimento de ambos os cônjuges na Conservatória do Registo Civil. Para recorrer a esta modalidade de divórcio, os cônjuges tinham que demonstrar responsabilidade. Assim, não tinham apenas que estar de acordo quanto à extinção do casamento mas também quanto a três assuntos importantes: o exercício das responsabilidades parentais dos filhos menores de idade depois do divórcio, o futuro da casa de morada da família e os alimentos devidos ao cônjuge que deles carecesse. O decretar do divórcio pelo Conservador do Registo Civil dependia, no entanto, da ratificação destes três acordos o que tinha por objectivo verificar se estes salvaguardavam os interesses de ambos os cônjuges bem como os interesses dos filhos. Neste sistema de equilíbrios estes três acordos necessários para requerer o divórcio por mútuo consentimento eram o "preço a pagar" pela simplicidade do processo e pela possibilidade de dissolução do casamento sem ter que revelar a causa.

O divórcio litigioso era pedido no Tribunal por um dos cônjuges contra o outro com fundamento numa determinada causa. Esta modalidade de divórcio apresentava duas variantes consoante o tipo de causa invocada. Assim, o divórcio litigioso podia ser pedido com base em causas subjectivas - a violação dos deveres conjugais - ou com base em causas objectivas - situações que faziam presumir a ruptura da vida em comum: separação de facto, alteração das faculdades mentais do outro cônjuge e ausência.

Apesar do reconhecimento do divórcio por mútuo consentimento e do divórcio baseado na ruptura da vida em comum, a ideia da culpa estava bem presente no sistema de divórcio português. A culpa relevava não só a nível das causas de divórcio - comportamentos culposos de um ou de ambos os cônjuges - mas também a nível dos seus efeitos. Na verdade, a declaração de culpa influenciava de forma notória a partilha dos bens do casal. A declaração de um 
dos cônjuges como culpado ou principal culpado iria determinar que - em certas circunstâncias, designadamente, se os cônjuges estivessem casados no regime de comunhão geral - a partilha dos bens do casal, na sequência do divórcio, se fizesse não de acordo com o regime de bens que tivessem escolhido em convenção antenupcial mas de acordo com o regime de comunhão de adquiridos. A lei determinava que o cônjuge culpado ou principal culpado não poderia receber na partilha mais do que receberia se o casamento tivesse sido celebrado segundo o regime da comunhão de adquiridos. Esta regra, que visava prevenir as situações em que o casamento pudesse servir como um meio de enriquecimento, era um exemplo perfeito das reminiscências do sistema de divórcio sanção na medida em que representava uma desvantagem económica para o cônjuge culpado ou principal culpado25.

Inspirada nos Princípios da Comissão Europeia para o Direito da Família sobre o Divórcio e os Alimentos entre Ex-cônjuges ${ }^{26}$, a Lei n. ${ }^{\circ}$ 61/2008, de 31 de Outubro, que operou a Reforma do regime jurídico do divórcio, eliminou o conceito de culpa. Quer isto dizer que deixou de haver qualquer referência à culpa no sistema de divórcio português. Assim, a Lei portuguesa conhece agora duas modalidades de divórcio: o divórcio sem o consentimento de ambos os cônjuges e o divórcio por mútuo consentimento.

Mais ainda, não há nenhuma sanção específica no âmbito do Direito da Família para a violação intencional e por isso "culposa" dos deveres conjugais que reciprocamente vinculam os cônjuges. Assim, tal violação será apenas sancionada nos termos das regras gerais da responsabilidade civil.

Assim, parece poder afirmar-se que a recente Reforma do Divórcio em Portugal operou uma espécie de "desvalorização" dos deveres

\footnotetext{
25 Cf. F. Pereira Coelho, G. Oliveira, Curso... cit., p. 616.

${ }^{26}$ K. BOELE-WOelKi et al, Principles... cit., p. 13.
} 
conjugais. Tal "desvalorização" reflecte, sem dúvida, a emergência de uma atitude não intervencionista do Estado no casamento e na família. O Estado começa a pensar o casamento como uma relação privada e, portanto, parece começar a considerar que os seus efeitos bem como a sua manutenção ou extinção devem ser remetidos a uma decisão dos cônjuges. De um modo semelhante ao que acontece, de resto, na união de facto. Com efeito, na união de facto, por definição, não existem regras que estabeleçam direitos e deveres recíprocos de respeito, fidelidade, coabitação, cooperação e assistência entre as partes; também não existe nenhuma sanção para a violação por um dos membros da união de facto de direitos e deveres morais que possam existir no contexto de tal relação bem como não existem regras que regulem o fim da relação.

\section{2. A "regulação" da união de facto}

Ao mesmo tempo que o casamento se aproxima da união de facto dada a tendência para a "desregulação" do casamento, a união de facto $^{27}$ é cada vez mais objecto de regulação.

As relações entre adultos são consideradas pelo Estado um assunto de grande importância pelo que, mesmo sendo reclamado um maior grau de autonomia neste âmbito, o Estado não pretende abster-se em as regular de algum modo.

Estamos perante uma área da vida social que é considerada demasiado importante para se tornar de tal forma privada que exclua qualquer tipo de intervenção do Estado. Na verdade, o Estado tem interesse em promover relações de cuidado que se caracterizam pelo apoio emocional e financeiro recíproco bem como em promover a igualdade e a justiça em tais relações. A prossecução deste objecti-

27 Para um estudo transversal da união de facto em Portugal bem como para uma análise crítica do processo legislativo sobre esta matéria, vide SALTER CID, N., A comunhão de vida à margem do casamento, Coimbra, Almedina, 2005. 
vo é levada a cabo através da protecção dos direitos da parte mais fraca, normalmente as mulheres e as crianças.

\section{III.2.1 A união de facto no direito português}

A intervenção do Estado nas relações de união de facto tem tido como suporte a finalidade de protecção da parte mais fraca bem como o objectivo de eliminar toda a discriminação real e legal em relação aos filhos nascidos fora do casamento, como de resto impõe a Constituição da República Portuguesa (art. 36. ${ }^{\circ}$, n. $^{\circ}$ 4, CRP). Tal intervenção assumiu em 1999 a forma de lei²8 - Lei da União de Facto - que veio de certa forma institucionalizar ${ }^{29}$ a união de facto ao regular os seus requisitos e os seus efeitos.

A novidade desta lei foi essencialmente reunir num só diploma as medidas de protecção da união de facto que já constavam de legislação anterior. Há, no entanto, a notar que a referida lei veio tornar claros os limites de relevância da união de facto ao fixar um prazo mínimo de durabilidade e uma lista de impedimentos ao seu reconhecimento. Quanto aos poucos aspectos inovadores, a lei veio esclarecer as dúvidas quanto à adopção conjunta de menores de idade pelos membros da união de facto, ao regime das prestações por morte de beneficiário da segurança social e veio consagrar um regime de protecção da casa de morada da família30. Esta lei, no entanto, restringia o seu campo de aplicação às uniões heterossexuais. O que fez com que o legislador viesse em 2001 ampliar o âmbito subjectivo da lei para passar a abranger as uniões de facto homossexuais ${ }^{31}$. Todavia a intervenção do Estado não se ficou por aqui.

\footnotetext{
${ }^{28}$ Lei 135/99, de 28 de Agosto.

29 Cf. F. Pereira Coelho, G. Oliveira, Curso... cit., p. 60

30 Cf. F. Pereira Coelho, G. Oliveira, Curso... cit., p. 61 e J. A. FranÇA Pitão, Uniões de facto e economia comum, Coimbra, Almedina, 2006, p. 5.

${ }^{31}$ Lei $7 / 2001$, de 11 de Maio. O texto desta nova lei não traz grandes novidades em relação ao texto da lei anterior. Destaca-se apenas o facto de a adopção conjunta
} 
Em 2010, viria a ser alterada a Lei da União de Facto ${ }^{32}$ estabelecendo quais os meios de prova da união de facto, consagrando uma protecção acrescida ao membro sobrevivo da união de facto no que respeita ao direito de habitação da casa de morada comum e ao direito ao uso do seu recheio (arts. 2..$^{\circ}$ A e 5. ${ }^{\circ}$, Lei 23/2010, de 30 de Agosto).

De uma leitura ainda que rápida do regime da união de facto pode concluir-se que o Estado oferece um mínimo de protecção legal aos membros da união de facto e aos seus filhos. A Lei da União de Facto é um bom exemplo do propósito, talvez inconsciente, de aproximar a união de facto do casamento. Na verdade, existem algumas semelhanças de regime na regulação legal do casamento e da união de facto.

Em primeiro lugar, a Lei da União de Facto determina um certo número de circunstâncias que impedem a união de facto de produzir efeitos. Em tais circunstâncias incluem-se a demência notória e a interdição ou inabilitação por anomalia psíquica; o parentesco em linha recta ou no segundo grau na linha colateral ou afinidade na linha recta; o casamento anterior não dissolvida e a condenação anterior de uma das pessoas como autor ou cúmplice por homicídio contra a pessoa do cônjuge do outro (art. 2. ${ }^{\circ}$, Lei da União de Facto). Estas circunstâncias são muito semelhantes aos impedimentos do casamento previstos no Código Civil (arts. $1601 .^{\circ}$ e $1602 .^{\circ}$, Código Civil). Eis o primeiro sinal da já mencionada tendência de convergência.

Ora, tendo em consideração os interesses públicos fundamentais que estão na base dos impedimentos matrimoniais, é razoável supor que, ao estabelecer circunstâncias semelhantes para impedir que a união de facto possa produzir efeitos, o legislador procurou evitar

ser apenas permitida aos membros de uma união de facto heterossexual e o estabelecer de limites mais apertados quanto à transmissão da casa de morada comum após a morte do arrendatário. J. A. FRANÇA PITÃO, Uniões de facto... cit., pp. 5-6.

32 Lei 23/2010, de 30 de Agosto. 
conceder efeitos favoráveis idênticos aos do casamento a pessoas impedidas de celebrar casamento ${ }^{33}$.

Em segundo lugar, a aproximação é também visível no que respeita aos efeitos da união de facto. Com efeito, a Lei da União de Facto apresenta uma lista de medidas de protecção dos membros da união de facto. Estas medidas coincidem com alguns dos efeitos do casamento; não correspondem aos tradicionalmente chamados efeitos pessoais - excepto quanto à adopção conjunta - e patrimoniais do casamento mas a maior parte destas medidas respeitam a benefícios que o Direito da Segurança Social atribui aos cônjuges. Pode observar-se igualmente aqui a tendência de aproximação ao casamento.

Em terceiro lugar, o fim da relação não é inteiramente livre. Na verdade, existe também alguma intervenção legal neste ponto. A maior parte das medidas de protecção da união de facto são dirigidas às situações de crise, que geralmente coincidem com o terminar da relação. Com efeito, grande parte destas medidas são inspiradas nas soluções legais para problemas idênticos decorrentes da extinção do casamento. A tendência de convergência continua.

Um dos principais problemas que resultam do fim da relação reside no futuro da casa de morada comum. A Lei da União de Facto prevê várias soluções que dependem do facto de a relação ter terminado por ruptura ou por morte de um dos membros da união de facto, bem como do facto de a casa ser propriedade de um ou de ambos ou de ser arrendada (arts. $4 .^{\circ}$ e $5 .^{\circ}$, Lei da União de Facto). Estas soluções são muito semelhantes às estabelecidas em caso de divórcio (art. 1793., ${ }^{\circ}$ Código Civil).

A morte de um dos membros da união de facto pode ter outras consequências. Se um dos membros da união de facto morre é

33 Cf. F. Pereira Coelho, G. Oliveira, Curso... cit., pp. 67-68. 
garantida um certa protecção social ao sobrevivo (art. $3 .^{\circ}$, Lei da União de Facto).

Assim, e embora persistam diversas diferenças, podem encontrar-se semelhanças entre o regime da união de facto e o regime do casamento. Na verdade, quando um dos membros da união de facto morre são-lhe atribuídos alguns dos direitos do cônjuge sobrevivo. Mais um sinal de convergência.

\section{Um "novo" conceito de casamento}

Tanto o casamento como a união de facto estão em mudança. Talvez estas mudanças sejam o reflexo de uma espécie de processo de reajustamento entre a noção social e a noção legal de casamento ${ }^{34}$. $\mathrm{Na}$ verdade, por toda a Europa estão a ser reconhecidas relações paramatrimoniais ${ }^{35}$.

A Reforma do Divórcio de 2008 bem como a Lei da União de Facto são dois bons exemplos de procura de um novo equilíbrio entre a autonomia do casal e a intervenção do Estado na família. Ambas expressam a tendência de convergência entre o casamento e a união de facto.

Creio que esta tendência se tornará cada vez mais clara e que no futuro as tensões entre o objectivo de promover a liberdade individual e o propósito de promover a solidariedade na família resultem numa maior aproximação entre o casamento e a união de facto.

34 Cf. S. PARKER, "The Marriage Act 1753: a case-study in family law making”, International Journal of Law and the Family, 1, 1987, p. 134.

35 Cf. M. ANTOKOLSKAIA, "Harmonisation of the family law in Europe: a historical perspective", in: VV. AA, M. ANTOKOLSKAIA (ed.), Convergence and divergence of family law in Europe, Antwerpen - Oxford, Intersentia, 2007, p. 17. 
O casamento "perderá peso" e a união de facto "aumentará de peso", as diferenças entre eles ficarão cada vez mais ténues até à emergência de um novo conceito de casamento.

O casamento será pois reinventado ${ }^{36}$. A morte do casamento será apenas um mito!

36 Cf. F. SWEnNEN, “O tempora, o mores...” cit., p. 144. 
(Página deixada propositadamente em branco) 